\title{
Serials.
}

\section{Open Access: Science Publishing as Science Publishing Should Be}

\author{
Jan Velterop
}

Full and unimpeded access (Open Access) to science literature is needed. It is not provided by the traditional subscription-based publishing model. Instead of criticizing Open Access and attacking its proponents, traditional publishers should make imaginative and innovative efforts to build their businesses around the needs of their customers rather than around their desire to continue a model that may be lucrative, but that is no longer satisfactory to science or society. Serials Review 2004; 30:308-309.

(C) 2004 Published by Elsevier Inc.

Recently the Open Access model of science publishing, as practiced by BioMed Central among others, has come under renewed and increasing attack from some of the world's largest traditional science publishers in various newspaper articles, at their presentations of financial results, in interviews, and in public debates. Furthermore, the concept of mandating publicly funded research results to be made openly and freely available, via repositories based at scientific institutions such as universities and research centers, has been called 'daft' by the chairman of one large science publisher, ${ }^{1}$ expressing a sentiment that seems to prevail among traditional publishers in spite of the fact that this same publisher has publicly expressed support for self-archiving in institutional repositories and has made quite a song and dance out of announcing its policy that allows self-archiving by the author.

The attack on Open Access is entirely understandable and logical. After all, there is much at stake and much to lose for the traditional science publishers. Who would not pull out all stops to defend a system that gives one monopolistic control over what is must-have content, without spending much in acquiring it, while enjoying a captive market? Any businessperson's dream! Publishers could be forgiven for taking the view that the model works and should not be changed. It does work. For them. Although perhaps its future potential is less secure.

From the vantage point of an academic, however, the picture looks less rosy. Full access to the fruits of earlier

Velterop is Director and Publisher of BioMed Central Limited, London WIT 4LB, UK; e-mail: velterop@biomedcentral.com. research efforts is of vital importance for any effective scientific research. In fact, not only access, but the need for unlimited further distribution, use in courses, reexamination, data mining and collecting, consolidation, meta-analysis, and the like-'purification by recrystallization' of scientific knowledge (Ziman) ${ }^{2}$-are so much a part of the modern scientific pursuit as well as of education that the possibility to do any or all of those things is as important as access itself. Unimpeded access is a necessary condition, albeit not sufficient in its own right.

This is the point where the shoe pinches: the traditional subscription model is no longer suitable for scientific information and communication because it needs to impose restrictions on access and usage of the literature, lifted only after payment, in order to survive. In the past, restrictions were accepted-and perhaps acceptable-as a necessary evil because the subscription model was simply the only practically possible one to sustain publishing when printed journals were the only means of disseminating validated scientific results.

Not any longer. We've had the World Wide Web revolution. The Internet makes it technically feasible to disseminate scientific information to anyone, anywhere, at any time and makes it possible to use the material in ways that were nothing but a dream before the advent of electronic publishing. The subscription model for access and use of scientific content has now become the principal limiting factor to the realization of that dream.

But business models can change. At BioMed Central we went back to first principles when devising a new, Open Access, publishing model. In the 1990s, one would have called it business reengineering. ${ }^{3}$ The resulting business model $^{4}$ makes it possible to make scientific information freely available to anyone inte- 
rested, rather like a public good, if you wish. Fitting, because most research is paid for from the public purse in the first place.

Open Access has obvious benefits for science and society. Is Open Access cheaper than the old model? Possibly, even quite probably (the monopoly is taken out of the system, encouraging a competitive marketplace), but to focus on the cost is somewhat missing the point. Science communication has always entirely been paid out of research funds, one way or another, either directly or indirectly, via institutional overhead charges. That does not change in an Open Access model. The "flow path" of the money is just different. The cost of publishing is, in the Open Access model, directly associated with the cost of the research effort. Publication costs are research costs. Without publishing the results, the research could easily be deemed not to have taken place at all. So the money flows in the direction of the publisher on behalf of the author rather than the reader. Payment is for dissemination rather than for access.

Open Access makes the spread of validated research easier throughout science and society alike. Not only researchers, but educators, policy makers, judicial authorities, industry will all have immediate access to the original scientific information, and the media, of course, making the haute vulgarization of science journalism, ${ }^{5}$ potentially much more reliable. Why should not they all benefit? Scientific research was always meant to be of use to society at large-Ziman calls science "public knowledge." And rightly so, as society pays for it.

Traditional publishers should stop whining and justifying an increasingly outmoded model. Instead, they should open their eyes to the new business opportunities that Open Access offers. There is much value to be created with services to the scientific community. But it is not to be found in the exploitation of information that has artificially been made scarce, particularly not where it concerns research results. One of the principal purposes of the creation is to share results as widely as possible. "Communication," after all, means sharing. Quite literally. ${ }^{7}$

It may seem that there is much value in the current subscription system, particularly to shareholders and other stakeholders, but that value shares characteristics with a soap bubble. Shiny, iridescent, but highly unstable. Wonderful to behold, but it can burst any moment. Poof! Value gone! Just as the soap bubble bursts when the water evaporates, so will the subscription bubble when the assumption evaporates that information is particularly valuable to the reader and access to it must be paid for. That assumption is evaporating fast, especially where it concerns scientific information. Scientific information is valuable, of course, but if access to it must be paid for by the reader, why is it that publishers do not have to pay for acquiring it from the author? That would be a normal and defensible trade in information: buying the material in from the originator and selling it on to the consumer. The interests of producer and consumer would balance, the publisher holding the bascule for a fee.

The fact that authors neither demand-nor even expect- to be paid, but instead submit their original research articles to the editors of a journal to be published, clearly shows that the balance of interests is different. For the vast majority of research articles, the interest of the author to publish (and therefore be read and cited) is much greater than the interest of the user to read it. This overwhelming interest on the part of the author is well captured in the phrase "publish or perish." Open Access publishing recognizes the imperative 'publish or perish' explicitly. In that model, payment for the process of peer review and publishing is made on behalf of-or by-the author rather than the reader. Some see in that a danger of vanity publishing. That danger might exist were there no peer review. But given that Open Access publishers make a living out of providing services for the proper organization and execution of peer review, its absence seems rather self-defeating. Paying does not guarantee publication, just as paying for a driving test does not guarantee passing it and getting a driver's license either.

The "publish or perish" ethic does result in what could be called "ego publishing." We are all subject to the rules of what could be described as a societal "ego-system" and the science community is no exception. Scientists have to 'market' themselves and their work. They have to present their scientific 'prowess' in the most effective way, for the sake of recognition, career advancement, and funding for future research projects. Open Access publishing combines these interests of the author with the interests of the scientific community as a whole in the most effective way.

It may be tempting for traditional publishers to hold on to a cozy and comfortably profitable position, but one cannot close one's eyes to changes that take place in the world. Nothing but the lack of innovation and imagination prevents traditional publishers from reengineering their businesses to suit the changing circumstances.

\section{Notes}

1. http://www.guardian.co.uk/business/story/0,3604,1277309,00. html.

2. John M. Ziman, "Information, Communication, Knowledge," Nature 224 (1969): 318-324.

3. Michael Hammer and James Champy. Reengineering the Corporation. New York: HarperBusiness, 1993.

4. The Open Access model BioMed Central uses applies to original research articles (primary literature, the overwhelming majority of the material published by BioMed Central) paid for 'at input' by or on behalf of the author(s) and not necessarily to review literature-except when also paid for at input—and other addedvalue services.

5. Ziman, "Information, Communication, and Knowledge."

6. Ibid.

7. "Communication," from Latin communicare, "to share." 